\title{
Approaches and typology to be applied for building information models verification
}

\author{
Elena Makisha, ${ }^{1, *}$ \\ ${ }^{1}$ Moscow State University of Civil Engineering, 26, Yaroslavskoye shosse, Moscow, Russia, 129337
}

\begin{abstract}
Experts from different countries are engaged in the study and development of verification systems of information models of construction projects. Nevertheless a problem of systematization and structuring of information on the types of inspections that the information model of the construction object can be subjected to still exist. In this article the author proposes a possible version of the classification of information model verification types using the faceted method, which determines the potential extensibility of this classification. The facet classification method involves the parallel division of a set of objects into independent classification groupings. It does not assume a rigid classification structure and preconstructed finite groupings. Classification groupings are formed by combining values taken from the corresponding facets. The article gives a detailed description of facets that may be applied.
\end{abstract}

\section{Introduction}

For a certain period of time experts from different countries are engaged in the study and development of verification systems of information models of construction projects. Under such a system there is a tool that allows checking the machine-readable presentation of project documentation (information model) for compliance with the requirements for it, which are also presented in machine-readable format. For a long time, these systems were considered as tools for the examination of design results, that is, checking for compliance with the requirements of normative and technical documentation. Now as considerable experience in the study of verification systems was gained, it becomes clear that the scope of inspections is not limited to the requirements of standards. Based on this there is a problem of systematization and structuring of information on the types of inspections that the information model of the construction object can be subjected to. In this article a possible version of the classification is proposed, which, if necessary, can be expanded.

\section{Materials and methods}

The theoretical substantiation of the classification proposed in this article is the research in the field of information model verification systems [1-5] - the faceted classification method was used as a tool.

\footnotetext{
*corresponding author:makishaev@mgsu.ru
} 
The facet classification method involves the parallel division of a set of objects into independent classification groupings. It does not assume a rigid classification structure and pre-constructed finite groupings. Classification groupings are formed by combining values taken from the corresponding facets. The sequence of facets in the formation of a classification grouping is given by the facet formula. The number of facet formulas is determined by possible combinations of features.

The main advantage of classification using the faceted method is the flexibility of the structure of its construction. Changes to any of the facets do not have a significant impact on all others. Greater flexibility leads to a good adaptability of the classification to the changing nature of the tasks for which it is created. With facet classification, it is possible to aggregate objects and perform information search on any combination of facets.

According to [6] facet method is to divide the many classified according to several classification criteria at the same time. To perform the classification in this way, it is necessary to determine the necessary features, each of which will form its own facet series (facet) consisting of subclasses of the object class in question.

\section{Results}

Five features were identified for classification of information model checks, on the basis of which the corresponding facets presented in table 1 were formed.

Table 1. Classification of inspections of information models of construction projects.

\begin{tabular}{|c|c|c|c|c|}
\hline $\begin{array}{c}\text { Subject of } \\
\text { verification }\end{array}$ & $\begin{array}{c}\text { Source of } \\
\text { requirements }\end{array}$ & $\begin{array}{c}\text { Range op } \\
\text { applicability }\end{array}$ & $\begin{array}{c}\text { Type of } \\
\text { verified } \\
\text { information }\end{array}$ & Life cycle stage \\
\hline $\begin{array}{c}\text { Entirety of } \\
\text { model }\end{array}$ & $\begin{array}{c}\text { Regulation } \\
\text { requirements }\end{array}$ & $\begin{array}{c}\text { All the buildings } \\
\text { and facilities }\end{array}$ & Geometric & $\begin{array}{c}\text { Verification of } \\
\text { design models }\end{array}$ \\
\hline $\begin{array}{c}\text { Quality of } \\
\text { model }\end{array}$ & $\begin{array}{c}\text { Construction } \\
\text { practice-base } \\
\text { requirements }\end{array}$ & $\begin{array}{c}\text { Specific types of } \\
\text { buildings and } \\
\text { facilities }\end{array}$ & Non-geometric & $\begin{array}{c}\text { Verification of } \\
\text { building models }\end{array}$ \\
\hline & $\begin{array}{c}\text { Customer } \\
\text { requirements } \\
\text { buildings or } \\
\text { facilities }\end{array}$ & $\begin{array}{c}\text { Verification of } \\
\text { service models } \\
\text { recommended } \\
\text { standards }\end{array}$ & & \\
\hline
\end{tabular}

\section{Facet "Subject of verification"}

\section{Completeness of the model}

The completeness of the model may be understood as:

- availability of all elements to be checked in the digital information model;

- presence of all attributes of elements to be checked in the digital information model;

- $\quad$ entirety of attributes of CIM elements to be checked;

- correspondence of attribute values to the range of valid values defined for them, which sets requirements for both the type of input data (for example, numeric, string, or Boolean) and directly for possible value variants. 
In other words, checking the completeness of the model may be called as a check on the verification minimum. The implementation of this check is fundamental from the point of view of ensuring the possibility of carrying out a basic check for compliance with certain requirements.

The requirements for the completeness of the model should be established by the relevant bodies authorized to conduct state expertise, or legal entities accredited to conduct non-state expertise, by identifying the elements, their properties and permissible values in the standards used for verification.

At the moment, software products have been developed that allow performing this type of checks (for example, simpleBIM). Approaches to automated verification of information models of capital construction projects developed by the countries considered in the previous report also include a stage of verification for completeness of the information model.

In addition, the model should be complete in terms of requirements for the composition of project documentation.

\section{Model quality}

The quality of the information model is understood as the correspondence of the actual values of attributes and relations between the elements presented in it, formal, established in the requirements.

Requirements for the quality of capital construction projects are established by various Advisory and mandatory standards.

This type of checks in some form has already been implemented both in replicated software products and in systems implemented at the level of a particular country. Further difficulties in trying to cover most of the existing normative documents are due to the formulation of the standards themselves, their ambiguity, inconsistency and confusion.

\section{Facet "Source of requirements»}

\section{Requirements of normative and technical documentation}

Requirements of normative and technical documentation are formed on the basis of officially approved standards of the country in which the design is carried out.

Taking into account the peculiarities of the standardization system of the Russian Federation, the following groups of inspections of this type can be distinguished:

- verification of compliance with national standards of the Russian Federation, including those introduced as national interstate, regional and international standards (GOST R and GOST);

- verification of compliance with codes of practice for design and construction;

- verification of compliance to specific technical requirements for the design and construction.

\section{Requirements based on design and construction practice and customer requirements}

In the course of activity of the design or construction organization on the basis of its practical experience recommendations on design of buildings and constructions which can be established further as requirements to information models of again under construction objects can appear. 
In addition, the customer can set their own additional requirements for a particular project.

Naturally, the requirements received on the basis of experience of the organization, and the requirements defined by the customer should not contradict normative and technical documentation.

\section{Requirements on the basis of voluntary standards}

In recent years, there has been a significant number of recommendation requirements, largely related to the impact of the construction site on the environment. Such regulations include LEED, BREEAM and DGNB, designed to motivate the construction of buildings that comply with the concepts of environmental friendliness, energy efficiency and sustainable development [7].

Undoubtedly, verification of the model for compliance with regulatory and technical documentation is a priority, but soon this approach will be relevant in the field of "green" standards.

Another example of such standards is the requirements of constructability, or, in another way, the degree of ease and efficiency with which building structures can be erected. Constructability depends to some extent on the quality of the project documentation: if the project documentation is difficult to understand and interpret, then such an object will be difficult to build $[8,9]$.

The concept of constructability is increasingly being explored by scientists from the US, Australia and New Zealand and could potentially be critical to improving the efficiency of the construction industry's processes.

The definition of constructability rules and their verification is currently an unsolved problem. The author did not identify such verification systems.

\section{Facet "Range of applicability»}

The applicability range is determined by the source of the requirements. Thus, in order to determine which objects are subject to the requirements of normative and technical documentation, it is necessary to analyze its scope. This section of the standard specifies whether it can be applied to all buildings and structures or whether there are restrictions in this regard.

In turn, the recommendations developed on the basis of design and construction practices may also apply to all objects, or a certain type of building, for example, a hospital or a courthouse, if the organization specializes in their design or construction.

The rules for a particular building project are generally related to space, circulation, ergonomic layout and location and are set by the customer or design firm.

\section{Facet "stage of the life cycle»}

As well as the object of construction, the information model is transformed, passing from one stage of lifecycle to another [10]. The General scheme of the life cycle of an object is determined in GOST 57296-2016 "an Integrated approach to the management of information life cycle man-made objects and environments. Description of data for mathematical modeling of life cycle processes. Fundamentals" [11, 12].

This means that the set of requirements for the information model will change accordingly. According to SP 301.1325800.2017 "Information modeling in construction. The rules of work organization of production and technical departments" [13] we can distinguish three stages of development of the information model: the design model, 
construction model and the Executive model. In this case, the construction model is a design model filled with new attributes, and the Executive model is formed by excluding from the construction model data relating exclusively to the production of construction works. [12]

Requirements for the design and construction information model are formulated in SP 301.1325800.2017. The specific composition of data, information and documents included in the operational information model, according to GOST R 57311-2016 "Modeling information in construction. Requirements for operational documentation of completed construction" [14], shall be determined by the organization-the owner of the object or the operating organization independently, based on its requirements for information. [12]

Thus, it is logical to assume that before using the model at a particular stage of the life cycle, it is necessary to verify its compliance with this stage, as shown in figure 1.

\section{Facet "Type of information to be checked»}

\section{Geometric information}

The verification of geometric information includes checks for the absence of intersections of model elements (collisions) or inconsistencies (overstated distances between elements), as well as the requirements of normative and technical documentation related to the assessment of sizes, areas, volumes.

The need to check for conflicts and inconsistencies is due to the possibility of performing separate sections of the project documentation by several groups of specialists in different software products. When you integrate all the parts into a single project are often formed intersections between the elements, which are called collisions, or inconsistencies. This type of checks is widely implemented in software products (NavisWorks, Solibri) and, in fact, is already a solved problem.

\section{Non-geometric information}

Non-geometric information refers to qualitative or quantitative characteristics that are not related to the geometric parameters of the object or element. For example, the temperature and humidity in the room, the requirements for the materials used and others.

A specific classification position is formed by obtaining a combination of selected values from each facet. Example of a possible position:

The quality of the model $\rightarrow$ the requirements of normative-technical documentation $\rightarrow$ all buildings or structures $\rightarrow$ geometric $\rightarrow$ verification of design models

That is, in this case, the model parameters will be checked for compliance with the requirements of regulatory and technical documentation that apply to all buildings and structures. In this case, the geometric information of the design model of the object will be checked.

Attributive information refers to qualitative and quantitative characteristics of an element or system that are not related to geometric parameters. For example, indoor temperature and humidity, requirements for the materials used and others. Cost information, in fact, is a subspecies of attribute information that allows you to determine the value of the element (system). 


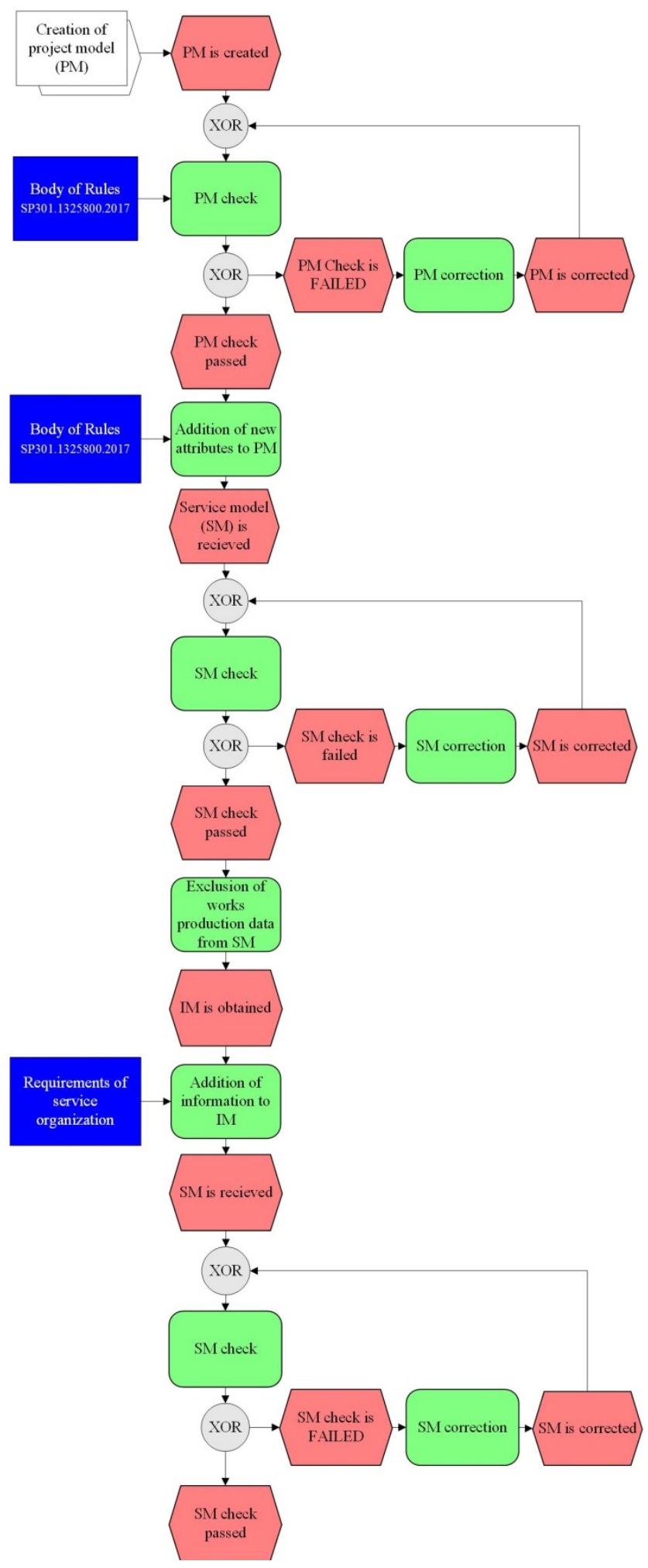

Fig. 1. Pilot plant scheme 


\section{Conclusions}

In this paper, we have proposed the classification of inspections, information models of construction projects. This classification provides an idea of the full scope of possible inspections and systematizes it. The use of the facet method determines the potential extensibility of this classification.

The primary task of verification of information models, according to the author, is to check the quality of the model in accordance with the requirements of normative and technical documents, as it is its results that can have a direct impact on the decision on the examination of project documentation, as well as on the safety of the constructed object. The approaches developed for this type of verification can be extended to other types of checks with the necessary adaptation. Evaluation of the completeness of the model is also mandatory as a way to enable basic verification of the information model.

\section{References}

1. C. Eastman, J.-M. Lee, Y.-K. Jeong, J. Lee, Automation in Construction, 18, 10111033 (2009).

2. W. Solihin, C. Eastman, Automation in Construction, 53, 69-82 (2015).

3. H. Lee, J.-K. Lee, S. Park, I. Kim, Automation in Construction, 71, 49-61 (2016).

4. E.V. Galkina, Sci. and tech. Volga region bulletin, 6, 95-97, (2018).

5. E.V. Galkina, Sci. Review, 21, 159-161 (2017).

6. GOST 7.74-96 Information and search languages, URL: http://docs.cntd.ru/document/1200004319 (date of access: 05.05.2019).

7. A.V. Ginzburg, M.Kh. Kangezova, Bulletin of Constr. Tech., 12 (1000), 33-35 (2017).

8. C. W. Schwinger, NASCC: The Steel conference proceedings (2011), URL: https://www.aisc.org/globalassets/modernsteel/archives/2011/03/2011v03_tips_for_design.pdf (date of access: 21.01.2019).

9. J. A. Gambatese, J. Hinze, M.E. Rinker, M. Behm, CPWR - The Center to Protect Workers' Rights (2005).

10. A.V. Ginzburg, Inf. Res of Russia, 5 (153), 28-31 (2016).

11. GOST R 57296-2016 Integrated approach to information management of the life cycle of anthropogenic objects and environments. Description of data for mathematical modeling of life cycle processes. Fundamentals, URL: http://docs.cntd.ru/document/1200142441 (date of access: 01.02.2019).

12. E.V. Makisha, S.A. Volkov, Eng, J. Of Don, 4 (2018).

13. SP 301.1325800.2017 Information modeling. Rules of work organization by production and technical departments, URL: http://docs.cntd.ru/document/555664724 (date of access: 01.10.2018).

14. GOST $R$ 57311-2016 Information modeling in construction. Requirements for operational documentation of completed construction projects, URL:http://protect.gost.ru/document 1 .aspx ?control $=31$ \&baseC $=6 \&$ page $=0 \&$ month $=10$ \&year $=2017 \&$ search $=57311 \& i d=205824$ (date of access: 01.10 .2018$)$. 